\title{
Erratum to: Surface grafting of bamboo fibers with 1,2-epoxy-4-vinylcyclohexane for reinforcing unsaturated polyester
}

\author{
Ming-En Fei $\cdot$ Tianshun Xie $\cdot$ Wendi Liu $\cdot$ Han Chen $\cdot$ Renhui Qiu
}

Published online: 31 October 2017

(C) Springer Science+Business Media B.V. 2017

\section{Erratum to: Cellulose DOI 10.1007/s10570-017-1497-1}

In the original publication of the article, an error occurred in the calculation of crystallinity index $(\mathrm{CrI})$ of bamboo fibers (BFs) based on the Segal method. The $C r I$ values of untreated and $3 \mathrm{wt} \%$ EVC-treated BFs were calculated from the following equation:

$C r I=\left[\left(I_{200}-I_{\text {Amorph }}\right) / I_{200}\right] \times 100$

where $I_{200}$ and $I_{\text {Amorph }}$ are the maximum intensity of the (200) lattice diffraction and the diffraction at $18^{\circ}$ of $2 \theta$ degree, respectively. The authors had mistakenly defined $I_{\text {Amorph }}$ as the intensity of the peak at $2 \theta=16^{\circ}$ instead of the minimum intensity at $2 \theta=18^{\circ}$

The online version of the original article can be found under doi:10.1007/s10570-017-1497-1.

M.-E. Fei · W. Liu · R. Qiu $(\bowtie)$

College of Transportation and Civil Engineering, Fujian

Agriculture and Forestry University, Fuzhou 350108,

People's Republic of China

e-mail: renhuiqiu@fafu.edu.cn

T. Xie

College of Material Engineering, Fujian Agriculture and Forestry University, Fuzhou 350108,

People's Republic of China

H. Chen

Institute of Forest Industry, Fujian Provincial Academy of

Forestry, Fuzhou 350012, People's Republic of China contributed by amorphous phase. Another error is that the peak at $2 \theta=16^{\circ}$ was identified as the $(001)$ reflection in Fig. 4 of the original publication. The peak should be attributed to the merged reflection of (1-10) and (110) patterns.

Based on the corrected diffraction patterns, the $\mathrm{CrI}$ values of untreated and $3 \mathrm{wt} \%$ EVC-treated BFs were calculated to be 64.01 and $60.66 \%$, respectively. The XRD curves of BFs with a baseline and corrected peak attribution are provided in Fig. 4 in this Erratum. Therefore, in the part "Crystallization of BFs" of "Results and discussion" section: (1) The sentences "The $2 \theta$ values of around $16^{\circ}$ and $22.5^{\circ} \ldots$ is sharp and intensive. These reflections are ... in the BFs, respectively." shall be deleted. (2) The sentence "the crystallinity index of the fibers slightly decreased from 42.46 to $39.53 \%$ after fiber treatment." shall be renewed with the corrected $\mathrm{CrI}$ values of untreated $(64.01 \%)$ and $3 \mathrm{wt} \%$ EVC-treated BFs $(60.66 \%)$. (3) The sentence "Thus, the EVC treatment did not cause obvious strength deterioration of fiber cell wall." shall be deleted. 

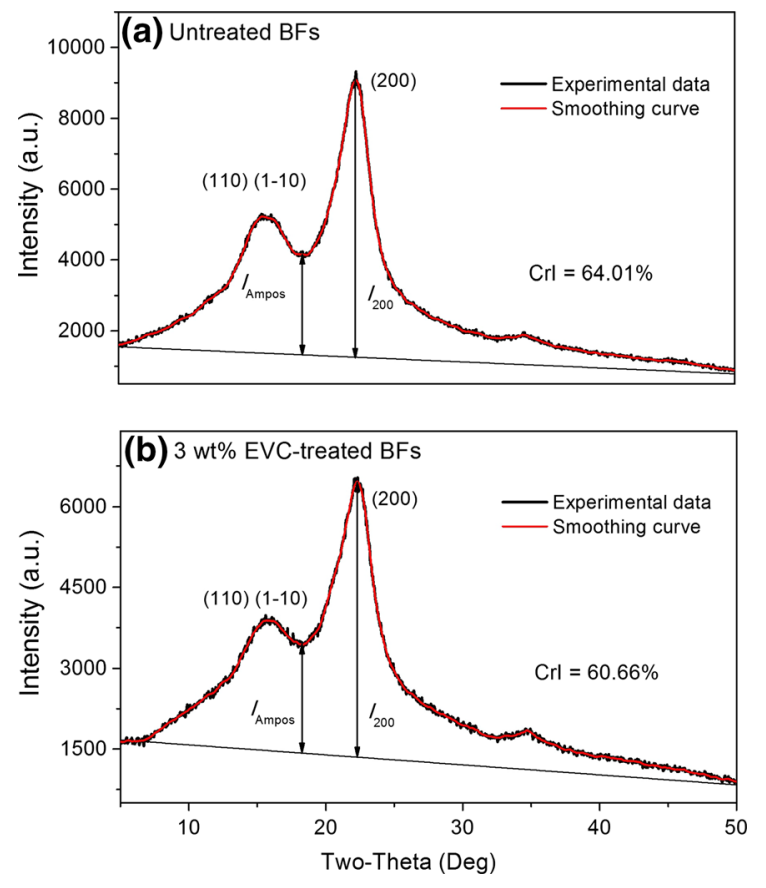

Fig. 4 XRD patterns of a untreated and b 3 wt $\%$ EVC-treated BFs 